\title{
Comparison between occupational noise measurement strategies: why is it important?
}

\author{
Susana Costa ${ }^{\mathrm{a},{ }^{*}}$ and Pedro Arezes ${ }^{\mathrm{a}}$ \\ ${ }^{a}$ Department of Production and Systems, School of Engineering of the University of Minho, Campus of Azurém,, \\ 4800-058 Guimarães, Portugal
}

\begin{abstract}
The international standard ISO 9612:2009, regarding the determination of occupational noise exposure through an engineering method, establishes a methodology for evaluating the exposure of workers to occupational noise, through the specification of three different strategies, namely: task-based measurement (TBM); job-based measurement (JBM) and; fullday measurement (FDM). In this work, questions are raised,«resulting in a literature review regarding the need to test the functionality of the three strategies, through the systematic comparison between them and analysis of their application impact at several levels. There is a need to test the compare these three strategies, since there are no peer-review studies in this domain. In fact, there are still no studies that systematically do the comparison between them and analyze the impact of their application at various levels, such as the precision and accuracy of the results, the required equipment, time spent and, most important, the estimation of the uncertainty associated to the measurements.
\end{abstract}

Keywords: Acoustics, uncertainty, accuracy, ISO

\section{Introduction}

Notwithstanding the efforts of the European Community regarding employees the health protection of exposed workers to occupational risks, occupational noise exposure is still a major problem among several industries $[1,6]$.

In Portugal, for example, a study by Bragança and Matos [1] reveals that daily personal occupational noise exposure level limit is often exceeded in Portuguese industries. Leal and Fradique [6] also conclude that the percentage of employees exposed to higher noise levels than those defined by the Portuguese legislation (Decreto-Lei n. ${ }^{\circ} 182 / 2006$, September 6th) is still high.

But how should one read those results? What methods did the researchers use? Were they well similar and well applied? Are those results to be trusted as real? Can they be compared between them?

ISO 9612:2009 was drawn with the purpose to help researchers and practitioners with different strategies according to different work situations, so that results are more reliable, adding for that purpose, the computation formulae of related uncertainties [3].

Thus, the international standard ISO 9612:2009, regarding the determination of occupational noise exposure through an engineering method, establishes a methodology for evaluating the exposure of workers to occupational noise, through the specification of three different strategies, namely: task-based measurement (TBM); job-based measurement (JBM) and; full-day measurement (FDM)[3]. However, given the fact that it is a very recent document, there is a need to test and compare these three strategies, since it seems that there are no published peer-review studies in this domain.

Seixas et al. have already compared TBM estimates with FDM, concluding that TBM measurements are important for exposures in which task time varies significantly, but also carry a substantial degree of error when a task has great inter-individual and variability within the different shifts. They also state that there is a need to improve the prediction to task-associated exposure [10]. Nevertheless, this study was presented in 2003, when the international

\footnotetext{
Corresponding author. E-mail: id3536@alunos.uminho.pt.
} 
standard ISO 9612:2009 did not yet exist. Meanwhile, on 2010 Mateus et al. tried to establish a comparison between the three strategies presented in the ISO standard, but since they have failed to do it in a systematic way, the need to ascertain it, in order to better understand its applicability, remains [7]. That is the scope of this work, to raise some questions regarding the need to test the functionality of the three strategies, through the systematic comparison between them and analysis of their application impact at several levels, including precision and accuracy of the results, required equipment, time spent and, estimation of the uncertainty associated to the measurements.

Taking into account the study developed by Ognedal and Turunen-Rise [9], some key points are easily foreseen. For instance, what is the performance of each strategy in terms of repeatability? What can one expect while choosing one strategy over another?

Questions need be answered so that the researcher is fully advised when opting for specific strategy. The comparison between the three strategies regarding accuracy, repeatability and reproducibility shall be established by means of Round Robin Tests (RRT), used by several authors $[2,4,8,9,11]$ as an important instrument of external quality control used to determine and/or verify the accuracy of measuring methods, enabling to determine a level of agreement between different methodologies.

Another question raised is: "How does the familiarity/experience of the researcher influence the result and how does it reflect on the expanded uncertainty?". In the study by Ognedal and Turunen-Rise,, conclusions state that, even though researchers had the guidelines of the engineering method (Nordtest Method), a significant percentage of researchers did not fulfil its requirements. Some of them did not even report the result in a correct manner [9].

It is thus important that the 3 strategies proposed by ISO 9612:2009 are applied by several different teams with different backgrounds, in order to evaluate how well researchers reproduce what is prescribed in the method, and if that's not the case (resembling the 2004 study by Ognedal and TurunenRise) it is important to evaluate why. In the latter study, some researchers commented that the text needed be re-written, since they found it not to be very explicit [9].

Another issue that deserves much attention is the uncertainty issue. Differences regarding uncertainty are patent in the document, but one can question whether the formulation is accurate since, once again, the strategies have not been enough tested, and there are not still any comparable values to make assessments from. Different background team testing will also allow checking if result overlapping exists and, consequently, if uncertainty formulation is correct.

Nevertheless, the main question and most important of all, still has no answer, not until this issue is taken into practice. That question is whether the methods are applicable or not, and the answer can only be given when these are sufficiently tested.

\section{Methodology}

Taking into account what other researchers have accomplished regarding this issue, some of their approaches shall be adapted and combined in the pursue of this objective, as follows.

\subsection{Comparison of the strategies}

RRT shall be performed to compare the three strategies, given it is a matter of performing a systematic study comparing quantification methods, as done by Castellote \& Andrade, Jaeschke et al., Oasmaa \& Meier, Ognedal \& Turunen-Rise and Tang \& Sorensen $[2,4,8,9,11]$.

A test to the uncertainty given by the three different measurements must be performed, in order to confirm and quantify the associated reliability, as done by Ognedal and Turunen-Rise [9], who compared an inter-laboratory method for measurement of noise in working environments. The 3 measurement strategies (TBM, JBM and FDM) shall be applied to all work stations selected (by different teams of research), so that all measurements can be done under the same conditions, using the predefined equipment, that is, the simultaneous use of sound level meter and dosimeter.

Having all measurements done under the same conditions, using the predefined equipment will, expectedly, grant a statistical basis for describing the variation of noise throughout the day and/or weeks [12].

The standard conditions, under which measurements will be applied for all employees and/or groups of employees, may ensure greater reliability and greater accuracy in results and by decreasing the subsequent error.

Resembling previous works, results shall be statistically treated in a daily and weekly basis, so as to put together a significant set of data on the indicators to be used and per work station [5]. 


\subsection{Accuracy, repeatability and reproducibility}

A systematic methodology must test the accuracy (trueness and precision), repeatability and reproducibility of the three measurement strategies, using, for instance, the principles defined in ISO 5725-2:1994, as done by Castellote and Andrade, who used the ISO 5725-2:1994 to compare methods for determining chloride transport parameters in concrete [2].

\section{Results}

In order to perform occupational noise measurements, practitioners and researchers need more than just a table indicating which one(s) to use given the work situation, but rather information regarding each strategy's accuracy, reproducibility and repeatability.

For a full comparison, it is also important to obtain data (exposure values) regarding the time needed to complete each measurement strategy.

One important issue is also uncertainty and its formulation, which must also be tested.

RRT are considered by most of the authors as an important external quality tool external quality used to determine and/or verify the accuracy of measuring methods, enabling to determine a level of agreement between different methodologies. Also, these tests may help clarify other sources of uncertainty not yet acknowledged and sort systematic errors.

RRT are also widely used by authors when intending to provide precision data according to ISO/IEC 17043 (02-2010) - Conformity assessment - General requirements for proficiency testing.

\section{Conclusion}

Some authors have tried to establish a comparison between the three strategies presented in the ISO 9612:2009, but have failed to do it in a systematic way, or at least they have not yet published their results. Therefore, and given also the fact that it is a very recent document, there are no published peerreview studies regarding its applicability. The standard needs to be tested regarding each strategy's accuracy, reproducibility and repeatability, in order to ascertain its applicability.
The information provided by the standard alone, in terms of when to use which strategy seems to be not enough for the researcher to, fully advised, engage on a single strategy.

The best way of readily having the substantial number of tests to the three strategies presented in ISO 9612:2009 needed to systematically compare them is performing RRT.

\section{References}

[1] L. Bragança and J. Matos,, Breve panorâmica do ruído industrial em Portugal, Guimarães, Acústica 2004.

[2] M. Castellote and C. Andrade, Round-robin test on methods for determining chloride transport parameters in concrete, Materials and Structures 39 (2006), 955-990.

[3] ISO 9612:2009 Acoustics - Determination of occupational noise exposure - Engineering method.

[4] M. Jaeschke, S. Audibert, P. Caneghem, A. E. Humphreys, R. Janssen-van Rosmalen and Q. Pellei, GERG round-robin test of Z-meters, a Burnett apparatus, and an interferometric device for $\mathrm{pVT}$ measurements, International Journal of Thermophysics 11 (1990), 157-168.

[5] A. Kaczmarska, W.Mikulski and B. Smagowska, Noise in office rooms, S. Petersburg, Eleventh International Congress on Sound and Vibration.

[6] I. M. Leal and J. Fradique, Evolução da exposição ao ruído nos locais de trabalho na indústria da região de Lisboa e Vale do Tejo. Guimarães, Acústica 2004.

[7] O. A. Mateus,, P. M. Arezes and C. A. Bernardo,, Impact of different measurement strategies on occupational noise exposure results in industrial environments, Lisbon, Internoise 2010.

[8] A. Oasmaa and D. Meier, Norms and standards for fast pyrolysis liquids: 1. Round robin test, Journal of Analytical and Applied Pyrolysis 73 (2005), 323-334.

[9] T. Ognedal and I. Turunen-rise, Inter-laboratory comparison of Nordtest test method for measurement of noise in working environment, NT Technical Report 586 (2004), Nordic Innovation Centre, Oslo, Norway.

[10] N. Seixas, L. Sheppard and R. Neitzel,, Comparison of task-based estimates with full-shift measurements of noise exposure, American Industrial Hygiene Association Journal, 64 (2003), 823-829

[11] L. Tang and H. E. Sørensen, Precision of the Nordic test methods for measuring the chloride diffusion/migration coefficients of concrete, Materials and Structures 34 (2001), 479-485.

[12] P. Voss, Noise in children's daycare centres, Magazine of the European Agency for Safety and Health at Work 8 (2005), 23-25. 